\title{
Students' Mathematical Connection in Programming Using GUI Matlab
}

\author{
Octavina Rizky Utami Putri \\ University of Muhammadiyah Malang \\ octavina@umm.ac.id
}

\begin{abstract}
The purpose of this research is to describe students' mathematical connection in making programming using GUI (Graphical User Interface). The subjects of this research are the students of Mathematics Education who are taking the Programming Language Course. The data were collected through the final task for making learning media of mathematics using GUI Matlab, field notes, and interviews. The data were analyzed based on mathematical connections with other sciences (Programming Languages). The result showed that students connect: (1) mathematics algorithms with flowcharts, (2) mathematics operations with operator symbols on Matlab, and (3) mathematics material with programming commands on Matlab. Students compose the algorithm before making learning media which then changed into the form of flowchart. Then, flowcharts created by students alongwith the algorithm are compiled. Learning media created by students involves the operator symbols on Matlab, which includes arithmetic, relational, and logical operators. Script of learning media created by students using programming commands on Matlabis in line with mathematics materials selected by students.
\end{abstract}

Keywords: mathematical connection, programming, GUI matlab

\section{INTRODUCTION}

Mathematics learning is required to facilitate students to develop higher-order thinking. One of the capabilities associated with higher-order thinking is the mathematical connection [1]. The researcher emphasized the mathematical connection to see the relationship of mathematical ideas with student representation [2]. These relationships include relationships between mathematical concepts, mathematics with everyday life, and mathematics with other sciences [3]. Various ways have been made to establish mathematical connections of students through mathematics learning [4], [5], [6]. One way is the application of technology in mathematics learning [7], [8]. The application of technology in mathematics learning has a positive impact on students' achievements and attitudes [9].

The curriculum for all levels and types of education should pay attention to the development of science and technology [10]. The statement is relevant to the curriculum of Mathematics Education Study Program of
University of Muhammadiyah Malang. This Study Program has a course of study, namelyComputation. One of the computation courses is the Programming Language. The purpose of this course is student can create learning media of mathematics of junior high school/ senior high school using GUI Matlab programming.

Matlab (Matrix Laboratory) is a system based on matrix for engineering and mathematical calculations [11]. Han and Valentine also explained that Matlab is an application for processing numerical data and programming language with basic element of array. One of the Matlab facilities is called GUI. The preview of GUI display is shown in Figure 1. GUI is an interactive feature involving two files: the figure file and $\mathrm{m}$-file. Figure file in Figure 2 contains a view that contains menus, buttons, radio buttons, drop down lists, and more. The M-file in Figure 3 contains a script to display and control the GUI [12].

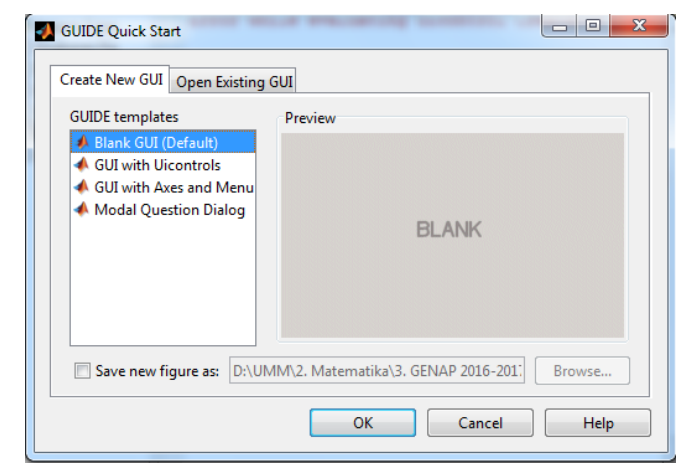

Figure 1. Preview of GUI

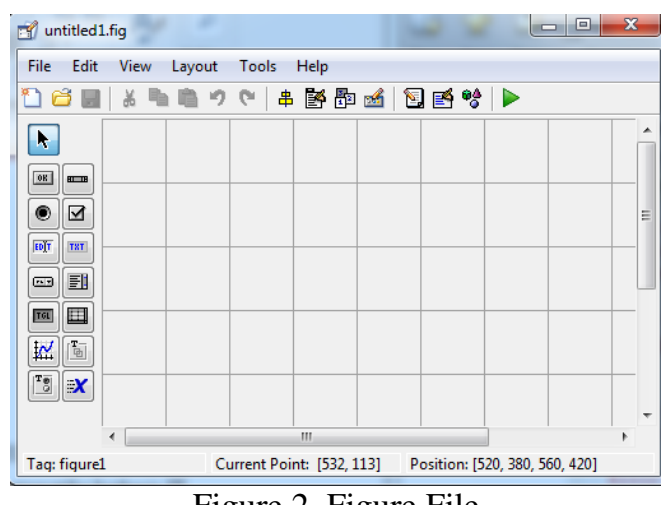

Figure 2. Figure File 


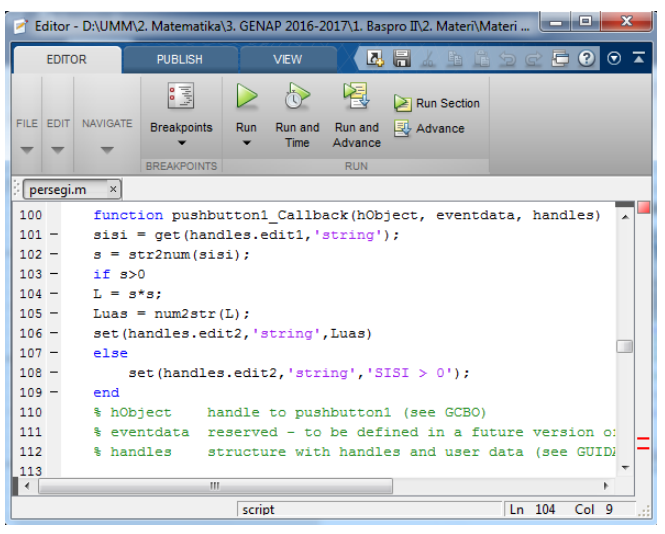

Figure 3. M-file

Mathematical connections in Programming have many benefits. The Waldspurger, d'Aspremont, and Mallat concluded that the matrix vector product is used in programming iterations [13]. Discrete mathematics has a relationship with the introduction of programming, and the data structure has a positive relationship with the completion of student calculus problems [14]. Therefore, this study aims to describe the students' mathematical connections in making programming using GUI Matlab.

\section{METHOD}

This descriptive qualitative research involves the students of Mathematics Education Studies Program as the subjects. The students are taking the Programming Language Course. In this case, students were given the final task of making the learning media of mathematics of junior high school/ senior high school using GUI Matlab. Furthermore, students were required to make reports and present media that have been made. The final duty sheet for them is creating learning media of mathematics using GUI Matlab. Field notes and interviews are the instruments used to obtain data of students' mathematical connections. All data were analyzed by reducing the data, presenting the data, and drawing conclusions. At the data reduction stage, the results of the report and the learning media were analyzed by finding a mathematical connection with another science that is Programming Language. The results of field notes and interviews when the students presented the learning media were used to strengthen the results of the students' task analysis. These three data are described in the form of narrative which then summed up to be a general description of the students' mathematical connections in making programming using GUI Matlab.

\section{RESULT}

Description of the students' mathematical connection was obtained from the analysis of reports and learning media, interviews, and field notes of student presentations. The students' mathematical connection in making programming using GUI Matlab is a connection mathematics with Programming Language which includes: (1) students connect mathematics algorithms with flowchart, (2) students connect mathematics operations with operator symbols on Matlab, and (3) students connect mathematics material with programming commands on Matlab.

The results of student reports consist of mathematics algorithms and flowcharts. Student-made mathematics algorithms are a series of sequential logical steps to solve mathematics problems. Student-made flowcharts are structured flow charts with certain symbols, which describe the initial process to the end of a program based on the algorithm the students make. Students create algorithms based on mathematics material selected, then create a flowchart in accordance with the algorithm created.

Mathematics algorithm created by students along with problem solving steps related to the purpose of instructional media that have been made. The objectives of learning media of mathematics are: (1) to facilitate junior high school/ senior high school students to learn math materials, (2) to test students' competence through exercises in media, and (3) to facilitate students to check the final result of a problem solving through simple calculator. The contents of learning media based on the objectives include: display material, samples, simple calculator, and exercise. One example of mathematics algorithms in accordance with the flowchart is made in the Learning Media of Statistics. The relevance of the algorithm and the flowchart especially to the calculator determines the average is described in the following steps:

Algorithm:

1. Start

2. Input your data

3. Calculate the mean

4. Show average results

5. Finish

Flowchart:

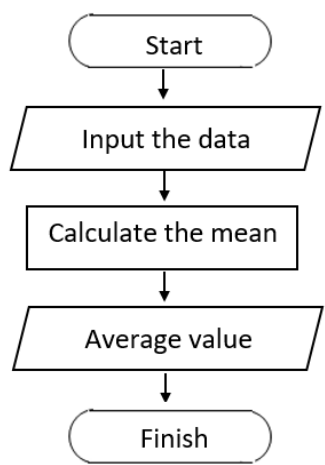

Figure 4. Statistics Flowchart

In the example above, the students connect the mathematics algorithm with the flowchart. The first step in the algorithm is the "start" symbolized by the "terminator" on the flowchart. The second step is to input data, symbolized by the symbol "input" on the flowchart. The third step is calculating the mean, then symbolized by "output" on the flowchart. The fourth step is to show the average result, on the flowchart symbolized by 
"output". The final step in the algorithm is finish, and symbolized by "terminator" in the flowchart.

The second finding of a mathematical connection with programming is that students connect mathematics operations with operator symbols on Matlab. Arithmetic operations are addition, subtraction, multiplication, and division, each represented by the arithmetic operator symbols,,$+- *$, and / onMatlab. Students use the four operator symbols in Matlab according to their respective functions. In learning media of mathematics created by students, one example is Social Arithmetic Media contains calculators looking for profit, loss, gross, netto, tara, single interest, and discount. The following table shows relationship arithmetic operation, arithmetic operator on Matlab, and the script on m-file contains the four operators according to their respective functions.

Tabel 1. Connection Between Arithmatic Operation and Operator on Matlab

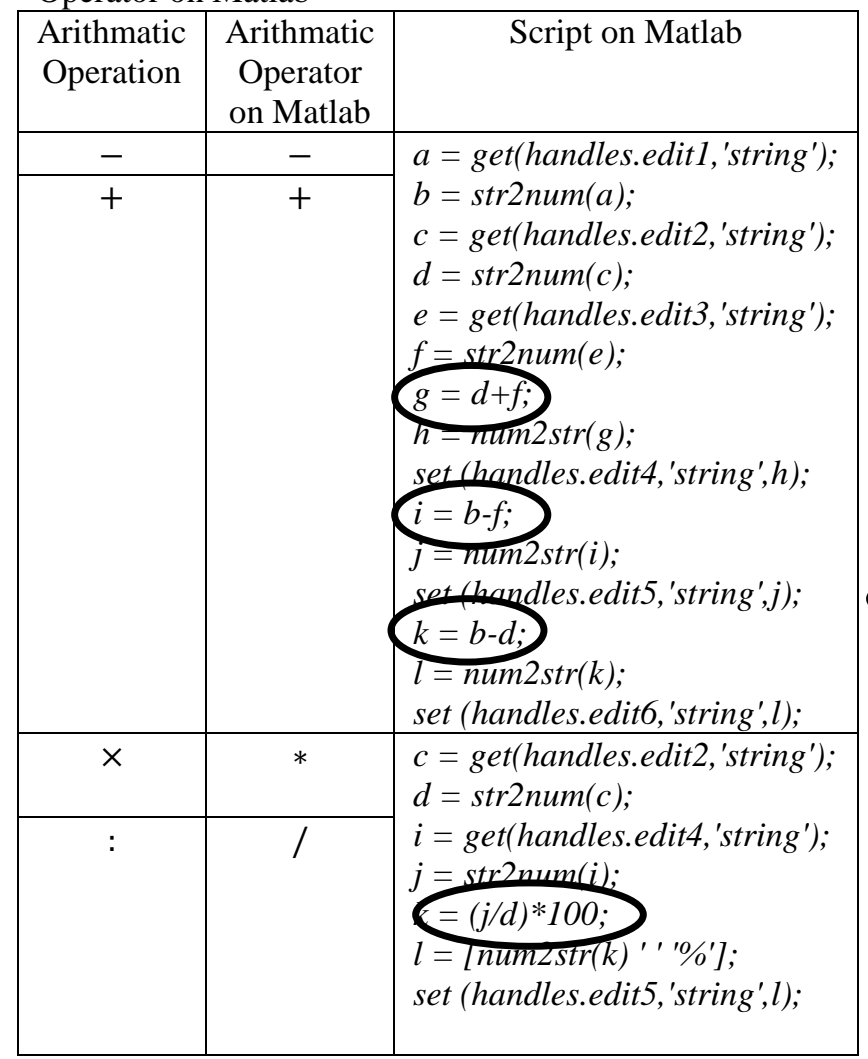

The script description on the Social Arithmetic Calculator is devoted to the Tara, Netto, Gross, and the Fortune Percentage Calculators. At Tara's, Gross, Netto Calculators, students use the symbol "+" to -determine gross $=$ netto + tara and symbol " $-"$ to determine netto $=$ gross - tara and tara $=$ gross - netto. Writing + and - on arithmetic operations with operators on Matlab has no different. At the Profit Percentage Calculator, students use the symbols "/" and "*" in the process of calculating the percentage gain. The percentage of profit is mathematically written percentage of profit $=$ profit $/$ (purchase price) $\times 100 \%$, then writing on Matlab is percentage profit $=($ profit $/$ purchase price $) * 100$. Based on the above findings, students connect arithmetic operations with arithmetic operators on Matlab according to their respective functions.

The second mathematics operation found in learning media is the use of the relation operator in Matlab in example $>$ and $==$. In Media Build Space, calculator developed by the student is Surface Areas and Volume of 2D Space. One of the calculators developed is Calculator of Surface Areas and Volume of Cube. This calculator contains inputs in the form of side length of the cube which is given the side length $>0$ condition, before processing the surface area and the volume of the cube. If this condition is met, then the process of calculating the surface area and volume of the cube come to the final result. If this requirement is not met, then the programmer warns the user that the length of the side must be $>0$. This indicates that the student is using "more than" operations on the created program. The "more than" symbol in the script is similar to the relational operation symbol on mathematics is " > ". The use of other operations is "equal to" symbolized by the sign $==$ in Matlab. The $==$ mark is used in the programming of the total scores True/False on the exercise questions. Here is an example of the use of relation operator $==$.

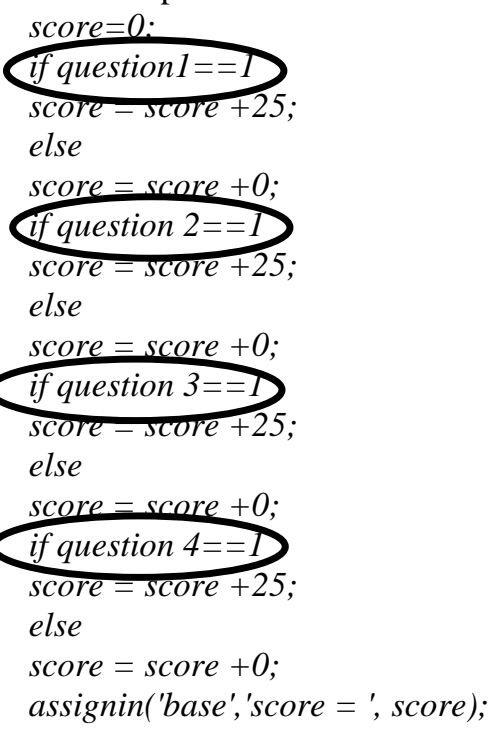

Example script use relation operator " $=="$ above, serves as a condition statement (terms) that must be met. The programmer gives the initial score $=0$. If the first problem is correct (question1 $==1$ ), then the initial score plus 25 . If the condition is not met, then the initial score plus 0 . The same analogy works for the explanation script scoring other question. There is a difference in use of the sign " == " with " = " in Matlab. The sign $==$ in Matlab is a relational operator that serves as a comparison of two statements, and is usually used for true / false truths. The sign = in Matlab is used to denote the equivalence of two statements that have the same value.

Students also connect operations on mathematical logic with logic operators on Matlab. The mathematical logic are conjunctions, disjunctions, implications, and biimplications, which are used in Mathematical Logic 
Media. Students make two inputs in the form of values of statement "True" or "False". In the script created, the student uses the "\&" operator for the conjunction, "|" for disjunction, the logic "if A else $\mathrm{B}$ " is used for the implication, and the logic " (xor)" is used for biimplication. This means that students can connect mathematical logic with the logic operator on Matlab.

The third mathematical connection in programming is a student connects mathematics material with programming commands on Matlab. Students create media with input "functions formula". The process created is to determine the derivative and integral functions of the input. One example of Derivative and Integral Media scripts is as follows.

global select

syms $x$ y z a b c;

$y=\operatorname{sym}($ get $($ handles.edit 1, 'string') $)$;

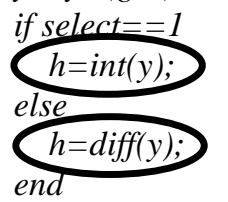

set(handles.edit2, 'string',char(h));

The above script is a derivative and integral process. In the script marked above, the int (y) command has function is the integral of $\mathrm{y}$, whereas the diff $(y)$ command has function is derived of $y$. In this case, the students connect mathematics materials are the Derivative and Integral with the diff and int command on Matlab.

In Statistics Media, students can also make the program specify mean, median, and mode. Sample script created by students is as follows.

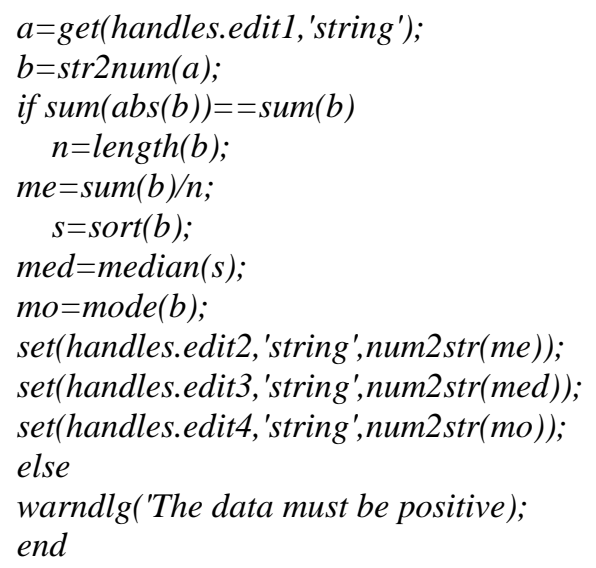

In the script above, students connect mathematics material with commands on Matlab. The material determines average $=\frac{\text { amount of data }}{\text { lots of data }}$ is interpreted as $m e=\operatorname{sum}(b) / n$ in Matlab programming. The student specifies the amount of data first specified in the command $\operatorname{sum}(b)$, then determines the amount of data stated in the command $n=$ length $(b)$ to obtain the $m e=\operatorname{sum}(b) / n$. Next, the students sort the data that is interpreted $s=$ sort $(b)$ in the script, then determine $m=$ median (s).Mode (b) in the script interprets commands to determine mode.

\section{CONCLUSION}

Mathematical connections of students in making programming using GUI Matlab is a connection mathematic with another science, that is Programming Language. Such connections include connections: (1) mathematics algorithms with flowcharts, (2) mathematics operations with arithmetic, relational, and logical operators on Matlab, and (3) mathematics material with programming commands on Matlab. This connection begins with the students developing a mathematics algorithm before creating a learning media. The algorithm that has been arranged then changed into the form of flowchart. There is a connection between the mathematics algorithm and the student's flowchart. Student-made learning media also involves operator symbols on Matlab, which include arithmetic, relational, and logic operators connected with mathematical operations. Learning media script created by students using Matlab programming commands is in line with mathematics material of junior high school/senior high school selected by students.

\section{REFERENCES}

[1] M.K. Mhlolo, M. Schafer, and H. Venkat, "The Nature and Quality of The Mathematical Connections Teachers Make," Phytagoras, vol. 33, pp. 1-9, 2012.

[2] C. A. Ormond, "Scaffolding The Mathematical Connections: A New Approach to Preparing Teachers for The Teaching of Lower Secondary Algebra," Australian Journal of Teacher Education, vol. 41, pp. 122-164, 2016.

[3] M. D. Siagian, "Kemampuan Koneksi Matematik dalam Pembelajaran Matematika," Journal of Mathematical Education and Science, vol. 2, pp. 58-67, 2016.

[4] A. Downton and P. Sullivan, "Posing Complex Problems Requiring Multiplicative Thinking Prompts Students to Use Sophisticated Strategies and Buid Mathematical Connections," Educational Studies in Mathematics, vol. 95, pp. 303-328, 2017.

[5] B. Kaur and T.L. Toh, "Reasoning, Communication and Connections in Mathematics: Year Book 2012, Association of Mathematical Educators", London: World Scientific Publishing Co. Pte. Ltd, 2012.

[6] J. A. Eli, M. J. Mohr-Schroeder, and C. W. Lee, "Mathematical Connections and Their Relationship to Mathematics Knowledge for Teaching Geometry," School Science and Mathematics, vol. 113, pp. 120-134, 2013.

[7] M. O. J. Thomas and Y. Y. Hong, "Teacher Integration of Technology into Mathematics Learning", International Journal for 
Technology in Mathematics Education, vol. 20, pp. 69-84, 2013.

[8] B. C. Gunhan and E. B. Guzel, "Integrating Technology into Mathematics Education: A Case Study from Primary Mathematics Student Teacher," World Academy of Science, Engineering and Technology International Journal of Education and Pedagogical Sciences, vol. 4, pp. 1577-1582, 2010.

[9] R. Eyyam and H. S. Yaratan, "Impact of Use Technology in Mathematics Lessons on Student Achievement and Attitudes," Social Behavior and Personality: an International Journal, vol. 42, pp. 31-42, 2014.

[10] Undang-Undang Republik Indonesia, Nomor 20, Pasal 36, 2013.

[11] K. Ogata, "Matlab for Control Engineers". London: Pearson Education, Inc, 2008.
[12] B.D. Hahn and D. T. Valentine, "Essential Matlab for Engineers and Scientists". Oxford: Elsevier Ltd, 2007.

[13] I. Waldspurger, A. d'Aspremont and S. Mallat, "Phase Recovery, MaxCut and Complex Semi definite Programming," Mathematical Programming, vol. 149, pp. 4781, 2015.

[14] A. Qahmash, M. Joy and A. Boddison, "To What Extent Mathematics Correlates with Programming: Statical Analysis," in Proc. International Conference on Computer Science Education Innovation \& Technology, 2015. 